\title{
Les Revenantes. Charlotte Delbo. La voix d'une communauté à jamais déportée, sous la direction de David Caron et Sharon Marquart
}

\section{Elisa Borghino}

\author{
(2) OpenEdition \\ Journals \\ Edizione digitale \\ URL: http://journals.openedition.org/studifrancesi/3856 \\ DOI: $10.4000 /$ studifrancesi.3856 \\ ISSN: 2421-5856 \\ Editore \\ Rosenberg \& Sellier

\section{Edizione cartacea} \\ Data di pubblicazione: 1 décembre 2012 \\ Paginazione: 609-610 \\ ISSN: 0039-2944

\section{Notizia bibliografica digitale} \\ Elisa Borghino, «Les Revenantes. Charlotte Delbo. La voix d'une communauté à jamais déportée, sous la \\ direction de David Caron et Sharon Marquart», Studi Francesi [Online], 168 (LVI | III) | 2012, online dal 30 \\ novembre 2015, consultato il 07 mars 2021. URL: http://journals.openedition.org/studifrancesi/3856 ; \\ DOI: https://doi.org/10.4000/studifrancesi.3856
}

Questo documento è stato generato automaticamente il 7 mars 2021.

\section{cc) (†) $\odot$}

Studi Francesi è distribuita con Licenza Creative Commons Attribuzione - Non commerciale - Non opere derivate 4.0 Internazionale. 


\title{
Les Revenantes. Charlotte Delbo. La voix d'une communauté à jamais déportée, sous la direction de David Caron et Sharon Marquart
}

\author{
Elisa Borghino
}

\section{NOTIZIA}

Les Revenantes. Charlotte Delbo. La voix d'une communauté à jamais déportée, sous la direction de David CARON et Sharon MARQUART, Toulouse, Presses Universitaires du Mirail, 2011, pp. 232.

1 Poesia e teatro: sono due le principali vocazioni di Charlotte Delbo, sopravvissuta all'orrore dei campi nazisti e autrice di testi paragonabili per bellezza ed intensità alle testimonianze di Primo Levi o Robert Antelme. Letta e amata soprattutto oltre-oceano, capace di ridefinire con uno sguardo e un linguaggio nuovi il dramma della deportazione, Delbo allude spesso al tema della comunità, risultante piuttosto dall'eterogeneità del gruppo che dalla differenza della classe sociale o dell'appartenenza identitaria. Non è un caso se la sua intera ricerca rimanda al gruppo stesso, ormai privato di radici e letteralmente de-portato. Sarà infatti nella vicinanza con il prossimo che Delbo cercherà una risposta - talvolta impossibile o introvabile alle proprie domande, accogliendo e prolungando nel lettore quello stesso spirito comunitario così severamente messo alla prova nel corso della prima metà del Novecento.

2 Nell'opera di Delbo la comunità è ovunque, presente non solo in quel noi collettivo, ma anche nei singoli avvenimenti che punteggiano il susseguirsi quotidiano di arrivi e partenze strazianti, appelli disumani che si ripetono ogni mattina, condivisioni generose di magre risorse. E, soprattutto, nella forza della testimonianza che 
coraggiosamente si propone e si impone, nell'intento di ripetere per non dimenticare. In fondo, quella voce corale che si compone e si scompone si dimostra all'origine di un appello collettivo al quale non è possibile rispondere senza liberarsi della propria singolarità, che, per quanto rassicurante, rimane suo malgrado circondata da un'aura più o meno consapevole di sordità e cecità.

3 La forza dell'autrice risiede nell'osservare, con uno sguardo attento ed indagatore, con un linguaggio semplice e mai eccessivo, la capacità di un popolo - quello francese - di cercare un barlume di vita anche nell'orrore, ora con la rappresentazione di una pièce teatrale, ora con la creazione artigianale di prodotti cosmetici, nell'unico intento di andare oltre un vissuto che pare ormai al di fuori di ogni schema precostituito, lontano dal controllo umano proprio perché alogico ed atemporale.

Il suo non è il semplice resoconto di un'esperienza o il riassunto di una parte di storia, quanto piuttosto il vero e proprio richiamo a una riflessione sulla verità da lei riportata, una partecipazione in prima persona che implica un'interazione diretta non solo con la parola scritta, ma anche con quella raccontata, con quella voce a lungo inutilmente soffocata che è nel contempo l'unico vero momento di rinascita di un io ingiustamente seppellito. L'oralità cessa dunque di appartenere alla sfera dell'intimità, per aprirsi verso un dialogo rivelatore, mosso dall'urgenza di dire che rende il fruitore primo testimone dell'orrore e al tempo stesso primo responsabile della trasmissione della vicenda.

5 Nel costituire una delle prime opere in francese dedicate a un'autrice la cui eccezionalità permette di ripensare i campi e la letteratura consacrata alla testimonianza, il volume rappresenta inoltre un importante punto di partenza per un percorso di ricerca identitaria e di riconsiderazione filosofica del vissuto di ognuno. 